\title{
Assessment of Spermatozoa Morphology under Light Microscopy with Different Histologic Stains and Comparison of Morphometric Measurements
}

\author{
Evaluación de la Morfología de los Espermatozoides bajo Microscopía Óptica con \\ Diferentes Tinciones Histológicas y Comparación de las Mediciones Morfométricas
}

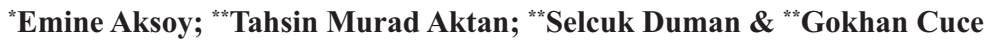

\begin{abstract}
AKSOY, E.; AKTAN, T. M.; DUMAN, S. \& CUCE, G. Evaluación de la morfología de los espermatozoides bajo microscopía óptica con diferentes tinciones histológicas y comparación de las mediciones morfométricas. Int. J. Morphol., 30(4):1544-1550, 2012.

SUMMARY: The aim was to examine the morphology of spermatozoa with different staining methods and aimed to find the better staining methods for morphology of spermatozoa in our study. Randomized 67 patients taken for the study who were admitted to Assisted Reproductive Techniques Unit. In the first part of the study, smears were stained with Hematoxylin Eosin (HE), Toluidin Blue (TB), Giemsa, Wright, ferrous Weigert haematoxylin stain, Orange G, eosin-aniline blue dye, Shorr Method, Papanicolau, Berg Method, Light Green stain, Acridine Orange (AO) and Janus Green dyes. In the second part of the study, smear preparations of 10 patients with normozoospermic were stained with HE, Toluidin Blue (TB), Shorr Method and Papanicolau. Four measurements were made including the middle piece, head length- head width and tail length for 200 spermatozoa with normal morphology. Comparisons were made between the stains that which showed a better morphology. Condensation assessment was not possible in smears stained with Shorr, Berg, Method, AO. Better assessment of condensation could be made in other stains. In the second part the smallest values belonged to of TB stain according to measurements of head of the spermatozoa. There was a significant difference at the head length with TB stain. Although measurements of Shorr and Papanicolau are close to each other and the largest values belonged to Papanicolau dye. It was concluded that measurement values in human sperm morphology could alter with the used staining method.
\end{abstract}

KEY WORDS: Spermatozoa; Morphology; Histological stains.

\section{INTRODUCTION}

Approximately $15 \%$ of married couples have infertility problems. Twenty percent of them originate from men, 30-40 \% originate from both men and women. So that half of the infertility couples have male-factor infertility (Spira 1986; Anafarta et al., 2007). ICS (intracytoplasmic sperm injection) was first performed by Palermo et al. (1992), many of the infertile couples could not be treated before, have been treated by ICSI.

Morphology of spermatozoa is an important for a successful fertilization and early embryonic development in assisted reproductive techniques (Kuster et al., 2004). Final Tygerberg Classification Criteria described by Kruger in 1986 and the WHO classification are the most important spermatozoa morphological classifications. According to Kruger's sperm, the head, neck and tail sections should be normal, the boundaries of the head should be smooth and oval and $70 \%$ of head should be coated by acrosome. The head of the sperm head length should be 4-5 $\mu \mathrm{m}$ and must have a width of 2.5-3.5 $\mu \mathrm{m}$. The length of the tail should be an average of $45 \mu \mathrm{m}$. The middle part must be thin and long and width should be less than $1 \mathrm{~mm}$, length should be of 1.5 times the length of the head. The tail should be thinner than middle piece, should be flat and not wrinkled, should not contain broken parts and cytoplasmic debris. In addition, the sperm should not have the neck, middle piece, tail abnormalities and a large cytoplasmic droplet more than half of the spermatozoon head in the neck area (WHO, 1999; Mehta et al., 2006).

The sperm must be stained for a better assessment of morphology. As there are many staining methods as

\footnotetext{
" Department of IVF, Central Laboratory of Education and Research Hospital, Konya, Turkey.

***University of Selcuk, Faculty of Meram Medicine, Deparment of Histology and Embryology, Konya, Turkey.
} 
Papanicolaou, haematoxylin, eosin, Giemsa, Diff-Quick for sperm staining (Sanchez et al., 1994). Morphological features of spermatozoa are expressed in numerical values. Methods used in the staining may cause a slight change in the measurement values of spermatozoa because fixatives can cause cells to shrink a little. For example, 3-5 $\mu \mathrm{m}$ length and $2-3 \mu \mathrm{m}$ wide measurements are considered normal for the head of spermatozoa in the method of Papanicolaou. These values change 5-6 and $2.5 \mu \mathrm{m}-3.5 \mu \mathrm{m}$ in the DiffQuick staining method. In both the middle piece should be $1 \mu \mathrm{m}$ thick, the length of this value should be up to $1.5 \mathrm{ti}-$ mes of this value. The tail section should be $45 \mu \mathrm{m}$ length tapering gradually (Irez et al., 2007). Because of these differences, we examined morphology of spermatozoa with different staining methods and aimed to find the better staining methods for laboratories in our study.

\section{MATERIAL AND METHOD}

In this study randomized 67 semen samples were obtained from patients for the study which were admitted to University of Selcuk, Faculty of Meram Medicine, Assisted Reproductive Techniques Unit. These patients have teratozoospermia $(n=25)$, Oligospermia $(n=20)$ and normozoospermia $(n=22)$.

Smear preparations were prepared from washed samples; the smears were dried at room temperature and fixed in methyl alcohol. In the first part of the study, smears were stained with (HE), TB, Giemsa, Wright, ferrous Weigert haematoxylin stain, Orange G, Eosin-aniline blue dye, Shorr Method, Papanicolau, Berg Method, Light Green stain, Acridine Orange (AO) and Janus Green dyes. Preparations were evaluated under the light microscope.

In the second part of the study, smear preparations of 10 patients with normozoospermic were stained with HE, Toluidin Blue, Shorr Method and Papanicolau. Evaluation of the sperm was based on Kruger strict criteria. Four measurements were done including the middle piece, head length- head width and tail length for 200 spermatozoa with normal morphology. Comparisons were made between the stains that which showed a better morphology and which is more appropriate for Kruger strict criteria by the statistical analysis. Analysis of the normal distribution of data was done.

Statistical comparisons between groups were performed with one-way analysis of variance (ANOVA) $(\mathrm{P}<0.05)$. Analysis of the normal distribution of data was examined with Kolmogorov-Smirnov Test.

\section{RESULTS}

Head, middle piece and tails of spermatozoa were seen clearly with HE. Acrosome core rate was extremely good in the form of light and dark purple (condensation). The stain was homogeneously distributed on the head and dark purple color was seen. The middle piece and tail were seen clearly and can be evaluated very well (Fig. 1). The ideal image was obtained by staining spermatozoa with $0.1 \%$ TB. The condensation of the head can be chosen by the whitish blue color. Condensation and morphology of the head can be selected clearly (Fig. 2).

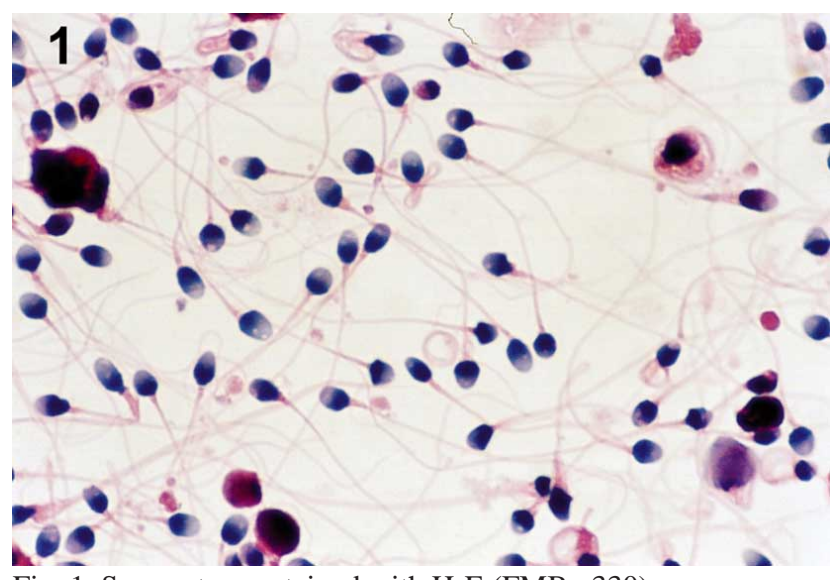

Fig. 1. Spermatozoa stained with H-E (FMBx 330).

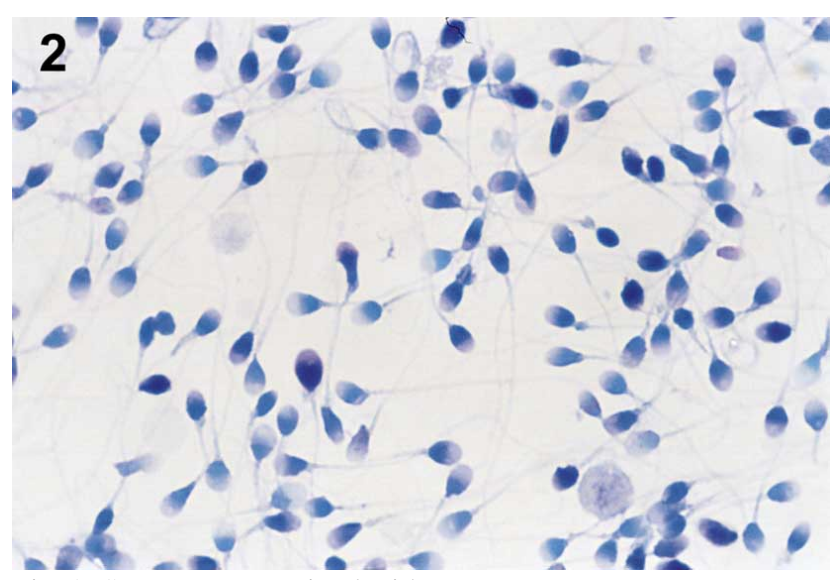

Fig. 2. Spermatozoa stained with TB.

The spermatozoa were stained dark blue purple with Giemsa. Head morphology and condensation could be seen very well but the middle piece and the tail did not seen clear. Spermatozoa were painted in shades of blue by Lilly Wright dye. Condensation in the head and morphology of spermatozoa were well-selectable. In an unexpected finding it was observed that some of spermatozoa including head damage, stained pink in the head. Spermatozoa heads were 
painted in black and navy blue with Weigert dye with ferrous H. Spermatozoa can be selected properly. Condensation could be distinguished on the head of spermatozoa and the head had been stained a dark purple color. Middle part and the tails were stained pink. Middle part was stained more than the other dyes. Flagellas are easily evaluated. Morphology of spermatozoa was clear and smooth with Orange G. Condensation could be seen in the head of the spermatozoa and spermatozoa stained fully orange. Flagella's can be selected easily (Fig. 4).

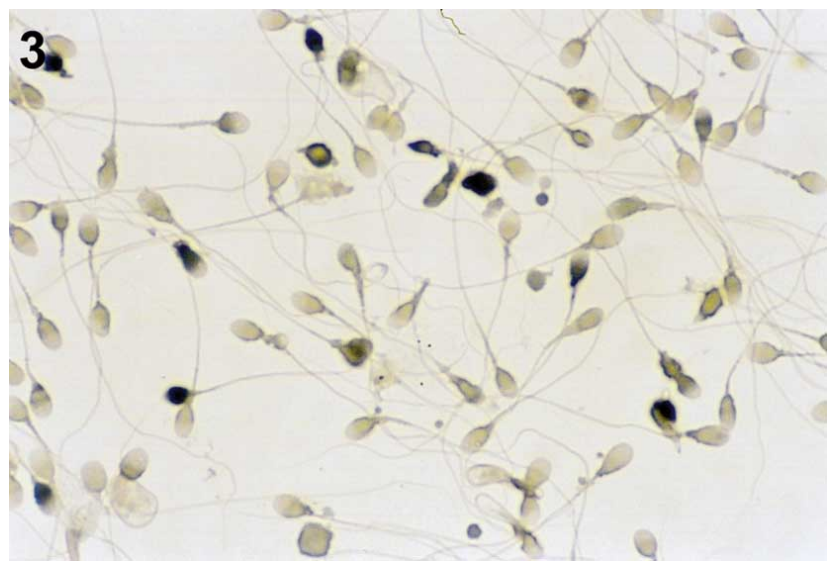

Fig. 3. Spermatozoa stained with Weigert's ferrous Haematoxylin.

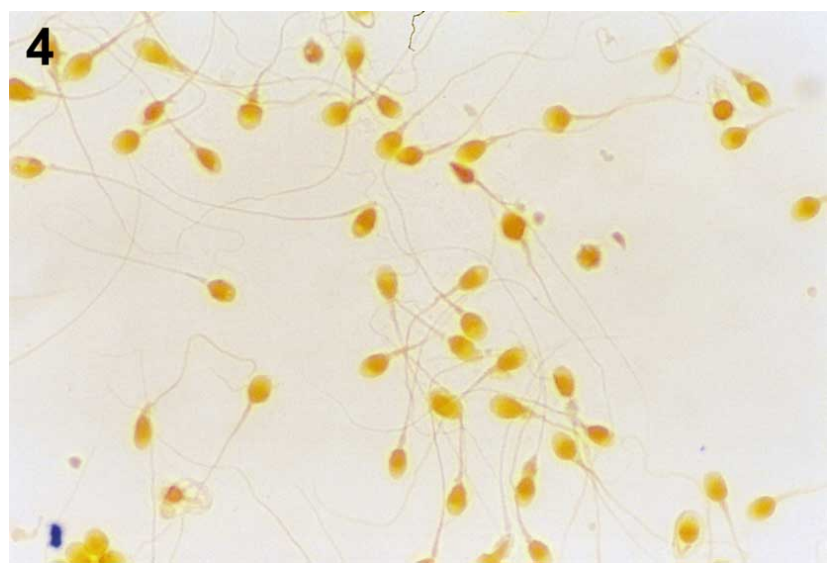

Fig. 4. Spermatozoa stained with Orange G.

Head of the spermatozoa stained light-dark-blue with Eosin-Aniline blue. Head morphology and the condensation were seen extremely well. Middle part and the flagella's can be seen well, but it was pale blue. The heads of spermatozoa stained yellowish brown with Papanicalou dye and condensation could be seen. Middle part and the flagella's were clearly stained dark brown (Fig. 5).

Spermatozoa morphology can seen well with light green dye. Condensation could be seen clearly and head of the spermatozoa stained green-blue. Middle parts and the flagella's stained green. The middle piece was pronounced. Flagella's were painted pale but was selectable (Fig. 6). The cell membrane stained a darker color than cytoplasm with Shorr that is why the morphology of spermatozoa and the cell borders could be seen very significant. The head is stained as a dark yellow color homogeneously. Condensation assessment could not be done but the middle part and flagella can be evaluated as very clear Therefore, all the morphological defects of spermatozoa could be easily evaluated (Fig. 7).

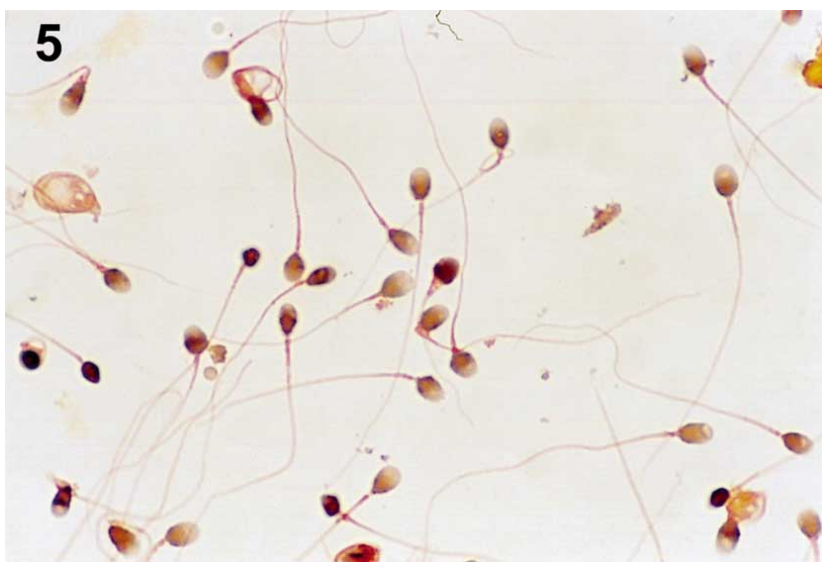

Fig. 5. Spermatozoa stained with Papanicolau.

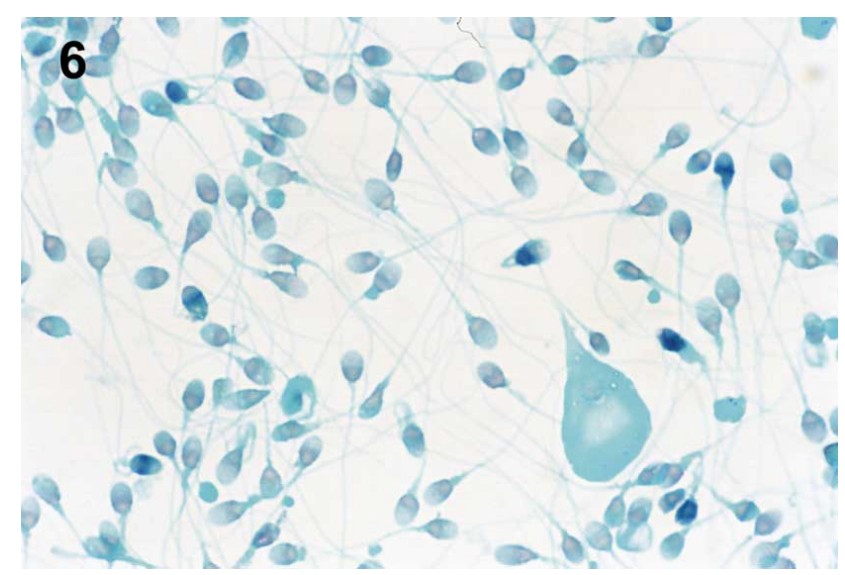

Fig. 6. Spermatozoa stained with Light Green.

The heads of spermatozoa were stained pale pink-lilac color with Berg Method. Morphology of spermatozoa was clear, but condensation of head could not be evaluated. Morphology of the spermatozoa was clear but condensation at the head was not evaluated with AO stain. When AO stain applied with haematoxylin, haematoxylin only stained the membrane around nucleus and spermatozoa observed like Y letter.

Morphology of spermatozoa with the supra vital dye Janus Green was clear, especially the middle piece (Fig. 8). Additionally, preparations of 10 normozoospermia patients 


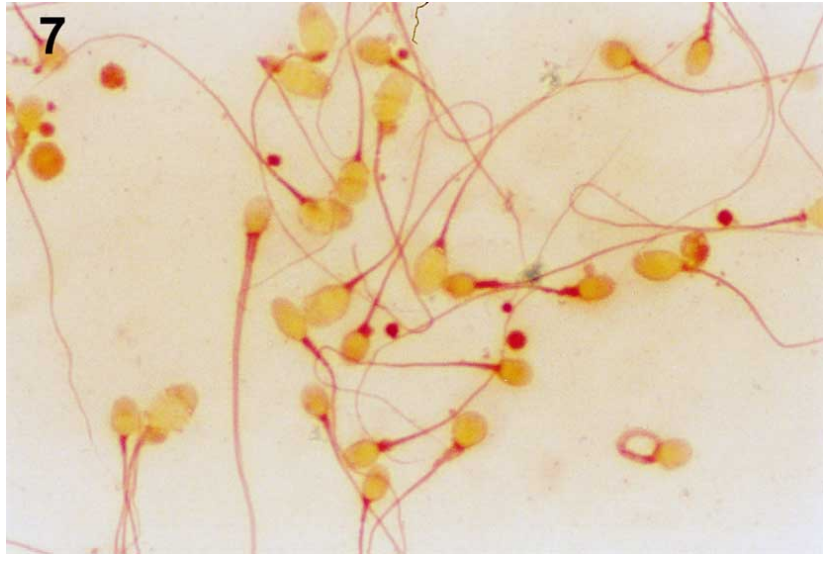

Fig. 7. Spermatozoa stained with Shorr.

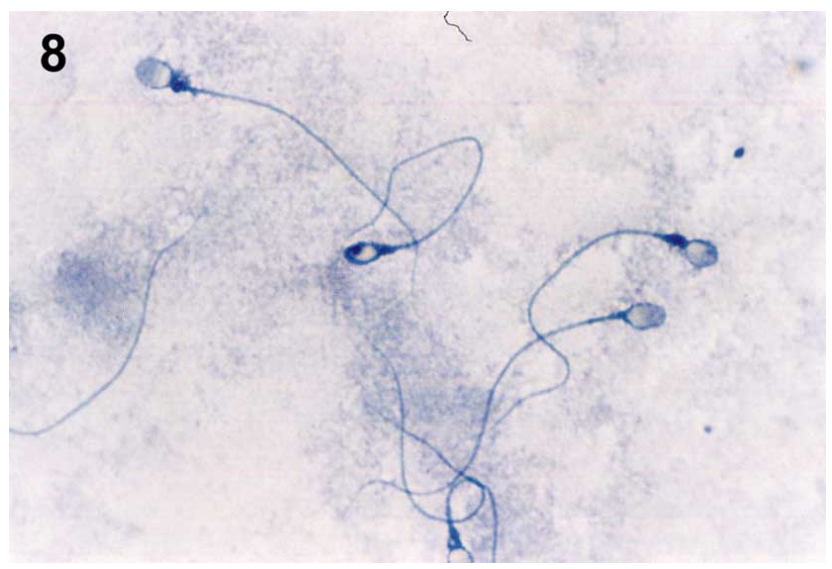

Fig. 8. Spermatozoa stained with Janus Green.

stained with H-E, TB, Shorr and Papanicolau were assessed according to Kruger's criteria. Spermatozoa were measured in terms of 4 parameters as head length, head width, middle part length and tail length. Statistical analysis were made using oneway variance analysis (ANOVA) and Post hoc Tukey HSD test and which stain showed better spermatozoa morphology and which was more appropriate for Kruger's strict criteria were determined. The smallest values belonged to TB according to measurements of head of the spermatozoa. There was a significant difference at the head length with TB stain. Although measurements of Shorr and Papanicolau are close to each other and the largest values belonged to Papanicolau stain (Table I) $(\mathrm{P}<0.028)$.

Table I. Measured values of head length and width in spermatozoa stained with HE, TB, Shorr and Papanicolau.

\begin{tabular}{lll}
\hline Group & $\begin{array}{l}\text { Length } \\
\text { Mean } \pm \text { SS }\end{array}$ & $\begin{array}{l}\text { Width } \\
\text { Mean } \pm \text { SS }\end{array}$ \\
\hline H-E & $4.75 \pm 0.15$ & $2.6 \pm 0.16$ \\
TB & $4.59 \pm 0.25$ & $2.56 \pm 0.04$ \\
Shorr & $4.86 \pm 0.15$ & $2.63 \pm 0.08$ \\
Papanicolau & $4.89 \pm 0.31^{*}$ & $2.69 \pm 0.25$ \\
P & 0.028 & 0.314 \\
\hline
\end{tabular}

\section{DISCUSSION}

Assessment of spermatozoa morphology is an important parameter in the diagnosis of infertile men. Due to the use of increasing amounts of IVF (in vitro fertilization) techniques, studies are also focused on the morphology of spermatozoa about the role in fertilization. Evaluation can be done with staining spermatozoa with a variety of methods from the fresh semen by electron, fast-contrast and light microscope. There are many staining methods to evaluate the morphology of spermatozoa (Uven et al., 1998). García-Herreros et al. (2006) used Hemaklor, Harris haematoxylin and PanOptic fast staining techniques to make standardization of the sampling methods, sample preparation and staining for the head of the spermatozoa with computerassisted morphometric analysis (CASMA). They concluded that Haematoxylin and Hemaklorun are the best staining methods for evaluation of sperm heads.

Soler et al. (2005) compared 3 different dye methods for assessment of spermatozoa morphometry with computerized Integrated Semen Analysis System (ISAS). They evaluated 200 spermatozoa cells stained with Hemacolor, Diff-Quik and harris haematoxylin. While they found all techniques were also useful in that used in staining of spermatozoa but Diff-Quick stain showed a significant difference.

TB is used in the evaluation of the nuclear chromatin of spermatozoa by identifying the absence or rupture of disulfide bonds. Beletti \& Mello (2004) examined relationship between spermatozoa morphology and spermatozoa chromatin condensation with TB and Feulgen reaction. TB is a effective stain for the evaluation of changes in spermatozoa chromatin. Our study is compatible with the knowledge of the literature. TB dye staining method is a simple method and allow simultaneous evaluation for morphology and condensation of spermatozoa. TB is an ideal dye for routine use in this area.

Chromatin condensation abnormalities of spermatozoas can be observed with Aniline Blue. The technique can be used to assess quality of spermatozoa (7). Avc1 (2006) used different fixation protocols to the semen samples and stained with Aniline Blue, Acridine Orange and Chromamycine A3 (CMA 3). The result for the quality of staining did not differ between the dyes. Hammadeh et al. (2001) aimed to identify the spermatozoa chromatin condensation values for assessment of male fertility. 165 semen samples had taken from 90 patients and 75 healthy individuals, stained with Aniline blue. They examined some 
classical semen parameters like the chromatin condensation, spermatozoa morphology, motility and progressive motility. They claimed that there was not a correlation between the chromatin condensation and the others. It was recommended that chromatin condense must be included, in routine laboratory observations.

Morel et al. (1998) randomly selected 47 patients applied for semen analysis, they examined the diversity of common morphological disorders in the human spermatozoa among individuals. In order to show their connection with the nuclear maturity, sperms stained with Aniline Blue, Spermatozoa morphology defects differences seen between individuals and they found a significant relationship between frequent of defects and degree of nuclear maturate. Our study is compatible with the knowledge of the literature. Aniline Blue dye provides the ideal image to measure the rate of acrosome head. Condensation and morphology can be assessed together.

Tartaglione \& Ritta (2004) examined the prognostic spermatological values of frozen dissolved spermatozoa to estimate in vitro fertility. Estimating plasma membrane and acrosome integrity are important values for normal functions of spermatozoa, for this aim, they examined smears stained with Trypan Blue and Giemsa. They concluded that these stains can be used for the prognosis of the fertility in the semen used for IVF.

Our evaluation was consistent with the literature of Giemsa and Wright stains. Condensation and head morphology of spermatozoa were well-selectable. The middle piece and tail could be seen. An unexpected finding that tail and head completely stained pink in the some of the spermatozoa which had damaged head morphology. A further study was suggested to explain the reason. Spermatozoa morphology and condensation were clear and smooth with Orange $\mathrm{G}$ stain. But staining process was too long that's why Orange G stain had no superiority.

Shorr technique is preferred in many laboratories due to the insufficient relationship in the results of IVF. Henkel et al. (2005) evaluated decreased motility of spermatozoa in elderly men with Shorr technique. The percentage of stained spermatozoa with normal and abnormal flagella's was evaluated and found a negative correlation between the stained abnormal flagella's and speed ratio and motility of the spermatozoa in elderly man.

Milingos et al. (1996) examined the sperm from 89 infertile couple and stained aniline blue and Shorr. They claimed that Shorr dye showed a better significant morphology than aniline blue. Our study is compatible with the knowledge of the literature. Shorr is a suitable dye for morphologic evaluation of spermatozoa but it is not considered to be appropriate for the assessment of condensation.

Papanicolaou's method allows assessment of morphological of healthy human spermatozoa and also allows the separation of immature germ cells. Menkveld et al. (1997) examined the relationship between human spermatozoa morphology and function of acrosome. Acrosome reaction evaluated at normal, small and large size in living and dead spermatozoa with triple stain. Spermatozoa with small acrosome were physiologically more susceptible to cell death and loss of acrosome. In addition, acrosome size reflects functional capacity of spermatozoa, thus the potential of male fertility can be evaluated.

Spermatozoa stained with Orange Acridine were very pale and could not be evaluated. When stained with $\mathrm{AO}+$ Haematoxylin, only the membrane around the nucleus stained with haematoxylin and then spermatozoa was seen in the form of the letter Y. New researches are recommended to investigate whether this image has a clinical value. Michael et al. (1987) stained and studied on spermatozoa and immature germ cells by using phase contrast microscope. With janus green B and tymol; head of spermatozoa, nuclear membrane, middle section was stained light green but nucleus was stained dark purple. In this method, janus green provided an excellent staining for evaluation of spermatozoa morphology.

In our study, spermatozoa heads appeared as whitishbluish light pale coloured, middle sections and tails were stained dark blue. Our study was appeared to be compatible with the literature and as the result of our study. Spermatozoa middle section which is a rich section for mitochondria's were revealed clearly and was displayed once again by janus green.

At second phase of our study, samples of 10 patients with normazoospermatozoa stained with HE, TB, Shorr and papanicolau and analysed by Kruger strict critters. Four different measurements including head length, head width, the mild section length and the tale length were done. We've had different results than literature data. Gago et al. (1998) used computer assisted image analysis systems with different staining methods for morphological evaluation of spermatozoa heads. They have found different results for spermatozoa head measurement parameters with Haematoxylein, diff-quick (Giemsa-Wright) and Hemaclor stain each. According to this results; it is concluded that spermatozoa head measurements are affected significantly 
by fixation procedures and staining techniques. When we compared haematoxylin and Giemsa-Wrihgt stains as morphologically we could not find a significant difference. Our study was not compatible with the literature in this sense. Root Kustritz et al. (1998) investigated spermatozoa morphological anomaly types and their percentages by using Giemsa-Wright stain, Eosin Y/nigrosin and Eosin B/ nigrosinstains with light microscope. In addition unstained samples were evaluated by using phase contrast microscope. They found higher percentile average of spermatozoa morphologies stained by Diff-Quick as a result of their study and concluded that preparation and staining techniques can change the evaluation of spermatozoa morphology.

Menkveld et al. (2003) examined different staining and washing procedure's affects spermatozoa morphology by using manual and computerised methods. They used Papanicolau and Diff-Quick staining methods at 20 semen samples. Manual assessments gave better results than computer assessments. Also spermatozoa morphological evaluations were better with once washed Diff-Quick stained smears than Papanicolau stained samples. In our study; morphological assessments were better with Papanicolau stain than Giemsa and Wright stain. In this sense our study was not compatible with literature data.

In our study morphometrical measurements of spermatozoa heads were smallest with TB stained samples. Shorr and Papanicolau stains have close measurements to each other but the maximal values belonged to Papanicolau stain. In the end we can say "for morphological assessment of spermatozoa, our special stains HE, TB, Shorr and Papanicolau are the best dyes as staining quality". Although many studies in literature are related to our work, there are only limited numbers of studies done for spermatozoa morphological assessment with comparing results of different stains. When it is thought the fact that having baby with reproduction techniques assists male infertility; the studies for morphological evaluations of spermatozoa's still remain important to select high quality spermatozoa's.

AKSOY, E.; AKTAN, T. M.; DUMAN, S. \& CUCE, G. Assessment of spermatozoa morphology under light microscopy with different histologic stains and comparison of morphometric measurements. Int. J. Morphol., 30(4):1544-1550, 2012.

RESUMEN: El objetivo fue examinar la morfología de los espermatozoides con diferentes métodos de tinción y encontrar los mejores métodos para su estudio. Fueron seleccionados para el estudio, de manera aleatoria 67 pacientes, quienes ingresaron a la Unidad de técnicas de reproducción asistida. En la primera parte del estudio, se realizaron y tiñeron frotis con hematoxilina eosina (HE), Azul de Toluidina (AT), Giemsa, tinción de Wright, Hematoxilina Férrica de Weigert, Anaranjado G, tinción eosina-anilina, método de Shorr, Papanicolau, método Berg, tinción verde brillante, anaranjado de acridina (AO) y tinción verde Janus. En la segunda parte del estudio, se realizaron frotis de 10 pacientes con normozoospérmicos y se tiñeron con HE, AT, Método Shorr y Papanicolau. Se realizaron cuatro mediciones: ancho de la cabeza, longitud de la cabeza, parte media y cola, sobre 200 espermatozoides con morfología normal. Se compararon las tinciones que mostraban mejor la morfología. La evaluación de la compactación no fue posible en los frotis teñidos con los métodos de Shorr, Berg y AO. Una mejor evaluación de la copactación podría hacerse en otras tinciones. En la segunda parte los valores menores correspondieron a la tinción de AT en relación a la medición de la cabeza de los espermatozoides. Hubo una diferencia significativa en la longitud de la cabeza con tinción de AT. Las mediciones en los frotis con técnicas de Shorr y Papanicolau fueron similares, con valores más altos bajo tinción de Papanicolau. Se concluyó que los valores de la medición morfológica en espermatozoides humanos podrían ser alterados según el método de tinción utilizado.

PALABRAS CLAVE: Espermatozoides; Morfología; Tinciones histológicas.

\section{REFERENCES}

Anafarta, K.; Bedük, Y. \& Arıkan, N. Principles of Urology. Ankara, Sun Publishing, 2007.

Avc1, B. Different fixation protocols with chromatin condensation of spermatozoa with sperm chromatin anomaly evaluation protocols. Uludag Univ. Med. Fac. J., 32:55-9, 2006.

Beletti, M. E. \& Mello, M. L. Comparison between the toluidine blue stain and the Feulgen reaction for evaluation of rabbit sperm chromatin condensation and their relationship with sperm morphology. Theriogenology, 62(3-4):398-402, 2004.
Gago, C.; Pérez-Sánchez, F.; Yeung, C. H.; Tablado, L.; Cooper, T. G. \& Soler, C. Standardization of sampling and staining methods for the morphometric evaluation of sperm heads in the Cynomolgus monkey (Macaca fascicularis) using computer-assisted image analysis. Int. J. Androl., 21(3):16976, 1998.

García-Herreros, M.; Aparicio, I. M.; Barón, F. J.; García-Marín, L. J. \& Gil, M. C. Standardization of sample preparation, staining and sampling methods for automated sperm head morphometry analysis of boar spermatozoa. Int. J. Androl., 29(5):553-63, 2006. 
Hammadeh, M. E.; Zeginiadov, T.; Rosenbaum, P.; Georg, T.; Schmidt, W. \& Strehler, E. Predictive value of sperm chromatin condensation (aniline blue staining) in the assessment of male fertility. Arch. Androl., 46(2):99-104, 2001.

Henkel, R.; Maass, G.; Schuppe, H. C.; Jung, A.; Schubert, J. \& Schill, W. B. Molecular aspects of declining sperm motility in older men. Fertil. Steril., 84(5):1430-7, 2005.

Irez, T.; Kucur, M. \& Is sman, K. Semen analysis. Andrology Laboratory Handbook. I’stanbul, Nobel Medical Publishing, 2007.

Kuster, C. E.; Singer, R. S. \& Althouse, G. C. Determining sample size for the morphological assessment of sperm. Theriogenology, 61(4):691-703, 2004.

Menkveld, R.; El-Garem, Y.; Schill, W. B. \& Henkel, R. Relationship between human sperm morphology and acrosomal function. J. Assist. Reprod. Genet., 20(10):432-8, 2003.

Menkveld, R.; Lacquet, F. A.; Kruger, T. F.; Lombard, C. J.; Sanchez Sarmiento, C. A. \& de Villiers, A. Effects of different staining and washing procedures on the results of human sperm morphology evaluation by manual and computerised methods. Andrologia, 29(1):1-7, 1997.

Michael, A. Y.; Drejer, J. O.; Bagger, P. V.; Detlefsen, G. U. \& Stakemann, G. Complete staining of human spermatozoa and immature germ cells combined with phase contrast microscopy. Arch. Androl., 19(3):217-21, 1987.

Milingos, S.; Comhaire, F. H.; Liapi, A. \& Aravantinos, D. The value of semen characteristics and tests of sperm function in selecting couples for intra-uterine insemination. Eur. J. Obstet. Gynecol. Reprod. Biol., 64(1):115-8, 1996.

Morel, F.; Mercier, S.; Roux, C.; Elmrini, T.; Clavequin, M. C. \& Bresson, J. L. Interindividual variations in the disomy frequencies of human spermatozoa and their correlation with nuclear maturity as evaluated by aniline blue staining. Fertil. Steril., 69(6):1122-7, 1998.

Palermo, G.; Joris, H.; Devroey, P. \& Van Steirteghem, A. C. Pregnancies after intracytoplasmic injection of single spermatozoon into an oocyte. Lancet, 340(8810):17-8, 1992.

Mehta, R. H.; Makwana, S.; Ranga, G. M.; Srinivasan, R. J. \& Virk, S. S. Prevalences of oligozoospermia and azoospermia in male partners of infertile couples from different parts of India. Asian J. Androl., 8(1):89-93, 2006.

Root Kustritz, M. V.; Olson, P. N.; Johnston, S. D. \& Root, T. K. The effects of stains and investigators on assessment of morphology of canine spermatozoa. J. Am. Anim. Hosp. Assoc., 34(4):348-52, 1998
Sánchez, R.; Villagrán, E.; Risopatrón, J. \& Célis, R. Evaluation of nuclear maturity in human spermatozoa obtained by spermpreparation methods. Andrologia, 26(3):173-6, 1994.

Soler, C.; Gadea, B.; Soler, A. J.; Fernández-Santos, M. R.; Esteso, M. C.; Núñez, J.; Moreira, P. N.; Nunez, M.; Gutierrez, R.; Sancho, M. \& Gadre, J. J. Comparison of three different staining methods for the assessment of epididymal red deer spermatozoa morphometry by computerized analysis with ISAS. Theriogenology, 64(5):1236-43, 2005.

Spira, A. Epidemiology of human reproduction. Hum. Reprod., 1(2):111-5, 1986.

Tartaglione, C. M. \& Ritta, M. N. Prognostic value of spermatological parameters as predictors of in vitro fertility of frozen-thawed bull semen. Theriogenology, 62(7):1245-52, 2004.

Uven, M.; Can, B. \& Saran, Y. Ultrastructural Changes in the Spermatozoa of Infertile Men. Turkiye Klinikleri J. Med. Res., 16:103-5, 1998.

WHO. Laboratory Manual for the Examination on Human Semen and Spermatozoa-Cervical Mucus Interaction. Cambridge, Cambridge University Press, 1999.

\author{
Correspondence to: \\ Emine Aksoy \\ Department of IVF \\ Central Laboratory of Education and Research Hospital, \\ Konya \\ TURKEY
}

Email: draksoyemine@hotmail.com

Received: 19-11-2011

Accepted: 22-05-2012 